\title{
Antimicrobial peptides of Lactobacillus salivarius K4 isolated from chicken intestine
}

\author{
Papassara Sangtanoo $^{\mathrm{a}}$, Kiattawee Choowongkomon ${ }^{\mathrm{b}}$, Wunrada Surat $^{\mathrm{a}}$, Sunee Nitisinprasert ${ }^{\mathrm{c}}$, \\ Anchanee Kubera ${ }^{a, *}$ \\ a Department of Genetics, Faculty of Science, Kasetsart University, Bangkok, Thailand \\ b Department of Biochemistry, Faculty of Science, Kasetsart University, Bangkok, Thailand \\ c Department of Agro-Industrial Technology, Faculty of Agro-Industry, Kasetsart University, Bangkok, \\ Thailand
}

*Corresponding author, e-mail: fsciacs@ku.ac.th

Received 13 Aug 2013

Accepted 14 Dec 2013

\begin{abstract}
Two cationic antimicrobial peptides, salvicin K (sal K) and antimicrobial-like bacteriocin $\beta$ (alb $\beta$ ) from Lactobacillus salivarius K4 were isolated from chicken intestine. In the active form, each peptide contains 47 amino acids with 2 cysteine residues. The antimicrobial activity showed that sal $\mathrm{K}$ could inhibit the food pathogens Enterococcus faecalis JCM 5803, Lb. plantarum ATCC 14917, and Streptococcus sp. TISTR 1030. The alb $\beta$ showed activity against E. faecalis JCM 5803, Leuconostoc mesenteroides subsp. mesenteroides JCM 6124, Lb. sakei TISTR 890, Lb. plantarum ATCC 14917, and Streptococcus sp. TISTR 1030. A high concentration of these bacteriocins was found to cause hemolysis in rat erythrocytes. Each peptide was predicted to have a mixed secondary structure of $\alpha$-helix, $\beta$-sheet, and random coil structure with one disulphide bond. Two antimicrobial peptides were found to be unstructured in Tris- $\mathrm{Cl} \mathrm{pH} \mathrm{9.} \mathrm{These}$ two peptides adopted an $\alpha$-helix conformation in 10\% SDS micelles (to simulate the bacterial cell wall). In zwitterionic dodecylphosphocholine micelles and liposome, these two peptides adopted a $\beta$-sheet structure. The results suggest that the $\alpha$-helix is an important conformation for these peptides to express their antimicrobial activity.
\end{abstract}

KEYWORDS: food pathogen, antimicrobial activity, structure and function relationship

\section{INTRODUCTION}

The production of small antibiotic peptides is a common defence strategy against bacteria displayed not only by microorganisms, but also by animals and plants ${ }^{1-3}$. These antibiotics are often small cationic membrane-active compounds that form pores in the target cells, disrupting membrane potential, and causing cell death. The antimicrobial peptides (AMPs) have been reported to kill or inhibit a variety of organisms or cells, including gram-positive, gramnegative bacteria, viruses, protozoa, parasites, fungi, and cancer cells ${ }^{4-6}$. The AMPs can be classified into four structural groups. First, the peptides exhibit the amphipathic $\alpha$-helical structure in a lipid membrane. These peptides are often unordered in solution. Second, the $\beta$-sheet peptides contain one or more disulphide bonds. The third group consists of loopstructured peptides containing one or more disulphide bonds. The fourth group comprises extended peptides with one or two amino acids predominating ${ }^{7-9}$. Well characterized antimicrobial peptides have a size varying from 30 to over 100 residues and consist of a wide range of different amino acids ${ }^{10}$. The mode of action of these peptides can be categorized into two mechanisms: transmembrane pore-forming mechanisms and modes of intracellular killing ${ }^{11,12}$. The transmembrane pore-forming mechanisms have been proposed for three models: barrel-stave model ${ }^{12,13}$, carpet model $^{14}$, and toroidal pore model ${ }^{15}$.

Bacteriocins are antimicrobial peptides synthesized by bacterial ribosomes ${ }^{16-18}$. They are produced by many bacterial species including several members of lactic acid bacteria (LAB). The bacteriocins from $L A B$ have a potential use as food preservatives to substitute the chemical preservation. There are many reported examples of LAB inhibition against the spoilage and pathogenic bacteria Pseudomonas fluorescens and Staphylococcus aureus ${ }^{19}$. Two antimicrobial peptides, salvicin K (sal K) and antimicrobiallike bacteriocin $\beta$ (alb $\beta)$, are produced from Lactobacillus salivarius $\mathrm{K} 4$ isolated from chicken intestine. A previous report described two peptides in Lactobacillus salivarius $\mathrm{K} 7$ isolated from chicken intestine. These peptides were found to function against the food pathogens Leuconostoc mesenteroides and Bacillus coagulans $^{20}$. In this study, sal $\mathrm{K}$ and alb $\beta$ were synthesized, their activities characterized, and their 
structures determined under various conditions. Our results show that these cationic peptides could inhibit some food-spoilage bacteria and exhibit an $\alpha$-helix structures in a membrane-mimicking environment.

\section{MATERIALS AND METHODS}

\section{Synthetic peptides}

Sal $\mathrm{K}$ and alb $\beta$ are cationic peptides. The active forms of sal $\mathrm{K}$ and alb $\beta$ contain 47 amino acids. These two peptides were synthesized without any modification at both $\mathrm{N}$ - and C-termini (AAPPTec). These peptides were confirmed by HPLC and MS analyses. The amino acid sequence of active sal $\mathrm{K}$ from $\mathrm{N}$ - to C-termini is KRYPNCTGKFLGGLAKGA ALGAISGGGVPGAVIGGNIGMVAGAISCL. The amino acid sequence of active alb $\beta$ from $\mathrm{N}$ - to $\mathrm{C}$ termini is KNGYGGSGIRWVHCGAGIVSGALM GSIGGNAWGAVAGGISGGIKSCR.

\section{Bacterial strains}

To determine the antimicrobial activities of peptides, food-spoilage bacteria were used. The bacteria included lactic acid bacteria group and gram-positive group. The lactic acid bacteria were Enterococcus faecalis JCM 5803, Leuconostoc mesenteroides subsp. mesenteroides JCM 6124, Lactobacillus sakei TISTR 890, Lactococcus cremoris TISTR 1344, Lactobacillus plantarum ATCC 14917, and Streptococcus sp. TISTR 1030. The gram-positive bacteria were Brochothrix campestris NBRC 11547, Listeria innocua ATCC 33090, P. fluorescence TISTR 358, Staphylococcus aureus TISTR 118, and Bacillus coagulans TISTR 1447. These bacteria were obtained from the Department of Biochemistry, Faculty of Science, Kasetsart University.

\section{Antimicrobial activity}

The antimicrobial activity of each peptide was tested by a broth microdilution assay ${ }^{9}$. The lactic acid bacteria were grown overnight in de Man, Rogosa, Sharpe (MRS) broth at $250 \mathrm{rpm}, 30^{\circ} \mathrm{C}$. The grampositive bacteria were grown overnight in tryptic soy broth (TSB) at $250 \mathrm{rpm}, 30^{\circ} \mathrm{C}$. The overnight cultures were diluted in either MRS or TSB to a final concentration of $10^{7}$ cells $/ \mathrm{ml}$. A stock of each peptide was prepared in water at $500 \mu \mathrm{g} / \mathrm{ml}$ and diluted twofold in serial dilution up to $15.6 \mu \mathrm{g} / \mathrm{ml}$. Then $10 \mu \mathrm{l}$ of each concentration of peptide was aliquoted into microtitre plates. For synergism experiment, sal $\mathrm{K}$ and alb $\beta$ were mixed in a ratio of $1: 1$ in each concentration. The 100- $\mu$ l diluted overnight cultures were then added into the plates. The samples were left overnight at room temperature and the culture turbidity visually examined. MICs are reported as an interval from $a$ to $b$, where $a$ is the highest concentration tested at which bacteria are still growing and $b$ is the lowest concentration that causes complete growth inhibition.

\section{Haemolysis activity}

Haemolysis in the microtitre plate was determined. The 2\% of rat erythrocytes was prepared in PBS buffer. A stock of each peptide was prepared in water at $500 \mu \mathrm{g} / \mathrm{ml}$ and diluted two-fold serial dilution to $15.6 \mu \mathrm{g} / \mathrm{ml}$ in microtitre plates. Each well containing $10 \mu \mathrm{l}$ of each concentration of peptides mixed with $100 \mu \mathrm{l}$ of diluted rat erythrocytes was left at room temperature overnight. For synergism experiment, sal $\mathrm{K}$ and alb $\beta$ were mixed in a ratio of $1: 1$ in each concentration. The $0.1 \%$ triton $\mathrm{X}-100$ was used as positive control for $100 \%$ haemolysis. The absorbance at $540 \mathrm{~nm}$ was monitored by NanoDrop $2000 \mathrm{UV}$ Vis spectrophotometer (Thermoscientific) to measure the release of haemoglobin. The percentage of haemolysis was calculated as $(A s-A b) /(A p-A b)$, where $\mathrm{As}=\mathrm{A} 540$ sample, $\mathrm{Ab}=\mathrm{A} 540$ PBS buffer, and $\mathrm{Ap}=\mathrm{A} 540$ positive control.

\section{Structural characterization by circular dichroism}

Circular dichroism (CD) spectra of peptides were measured by J-715 spectropolarimeter (Jasco, Japan). The concentrations of sal $\mathrm{K}$ and alb $\beta$ were prepared at $0.1 \mathrm{mM}$ in various conditions which were (i) Tris-Cl $\mathrm{pH} 9$, (ii) $10 \%$ SDS $\mathrm{pH} 9$, (iii) $2 \mathrm{mM}$ dodecylphosphocholine (DPC) $\mathrm{pH} 9$, and (iv) liposomes $\mathrm{pH} 8$. The spectra were measured at room temperature in $1-\mathrm{mm}$ path length quartz cell. The scanning speed was $50 \mathrm{~nm} / \mathrm{min}$ from 190-260 nm. Each spectrum was the average of three scans. The percentage of the secondary structures was analysed by SELCON Version $3^{21}$.

\section{Sequence alignment and structural prediction}

Amino acid sequences of sal $K$ and alb $\beta$ were aligned in the antimicrobial peptide database aps. unmc.edu/AP/main.php ${ }^{22}$ and analysed for protein structure prediction in www.predictprotein.org ${ }^{23}$. The sequence with the highest similarity for each peptide was shown. The percentages of secondary structure, disulphide bond, and transmembrane region were predicted.

\section{RESULTS}

\section{Antimicrobial activity of sal $K$ and alb $\beta$}

The active forms of sal $\mathrm{K}$ and alb $\beta$ were synthesized. Each peptide was diluted to concentration in the range 
Table 1 MICs of bacteriocins sal $\mathrm{K}$ and alb $\beta$.

\begin{tabular}{lcc}
\hline Bacterial strain & \multicolumn{2}{c}{$\mathrm{MIC}(\mu \mathrm{g} / \mathrm{ml})$} \\
\cline { 2 - 3 } & $\mathrm{sal} \mathrm{K}$ & $\mathrm{alb} \beta$ \\
\hline E. faecalis JCM 5803 & $15.6-31.3$ & $15.6-31.3$ \\
Leuconostoc mesenteroides subsp. mesenteroides JCM 6124 & $>500$ & $62.5-125$ \\
Lactobacillus sakei TISTR 890 & $>500$ & $250-500$ \\
Lactococcus cremoris TISTR 1344 & $>500$ & $>500$ \\
Lactobacillus plantarum ATCC 14917 & $15.6-31.3$ & $250-500$ \\
Streptococcus sp. TISTR 1030 & $15.6-31.3$ & $15.6-31.3$ \\
\hline
\end{tabular}

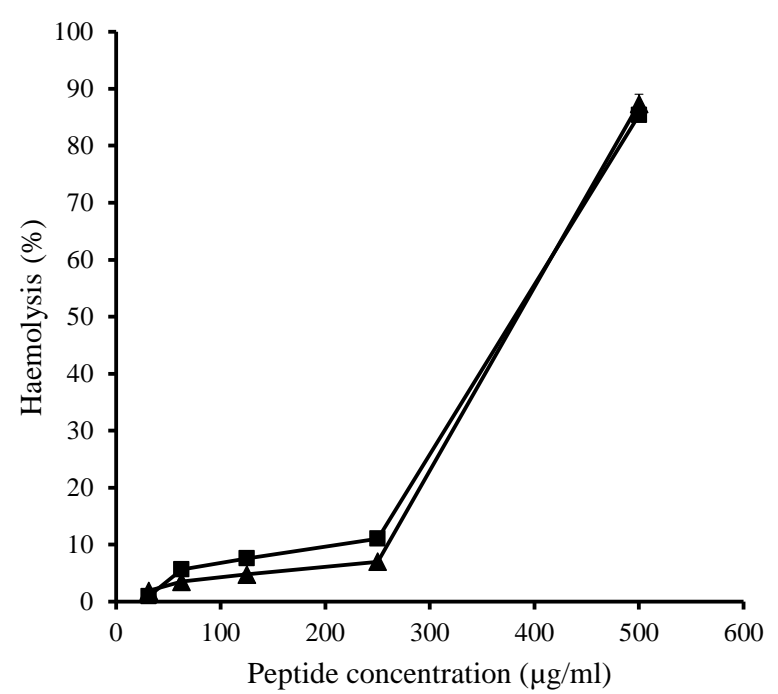

Fig. 1 Haemolysis activities of sal $\mathrm{K}$ and alb $\beta$ were tested against rat erythrocytes. Triton-X $100(0.1 \%)$ was used as positive control for $100 \%$ haemolysis and PBS buffer for negative control.

15.6-500 $\mu \mathrm{g} / \mathrm{ml}$. Table 1 shows the antimicrobial activities (MICs) of each peptide against 6 strains of lactic acid bacteria. Sal K shows activities against E. faecalis JCM 5803, Lb. plantarum ATCC 14917, and Streptococcus sp. TISTR 1030, while alb $\beta$ expresses activities against E. faecalis JCM 5803, Leuconostoc mesenteroides subsp. mesenteroides JCM 6124, Lb. sakei TISTR 890, Lb. plantarum ATCC 14917, and Streptococcus sp. TISTR 1030. Synergistic activity of these peptides was not found. For activity of peptides against gram-positive bacteria, only alb $\beta$ had activity against Brochothrix campestris NBRC 11547. Both peptides showed MICs $>500 \mu \mathrm{g} / \mathrm{ml}$ against other gram-positive bacteria.

\section{Haemolytic activity of sal $K$ and alb $\beta$}

Haemolytic activity of sal $\mathrm{K}$ and alb $\beta$ shows similar results (Fig. 1). The concentrations of these peptides were found up to $500 \mu \mathrm{g} / \mathrm{ml}$ to obtain $90 \%$ of haemol- ysis. The $\mathrm{LC}_{50}$ values of sal $\mathrm{K}$ and alb $\beta$ were 371.8 and $366.2 \mu \mathrm{g} / \mathrm{ml}$, respectively. Synergistic activity of these peptides was not found.

\section{Structural characterization by circular dichroism}

$\mathrm{CD}$ spectra of sal $\mathrm{K}$ and alb $\beta$ were measured in different conditions: (i) $20 \mathrm{mM}$ Tris- $\mathrm{Cl} \mathrm{pH}$ 9, (ii) $10 \%$ SDS, (iii) $2 \mathrm{mM} \mathrm{DPC}$, and (iv) liposome. Sal K and alb $\beta$ structures were found unordered in the Tris- $\mathrm{Cl}$ buffer solution. In the presence of anionic micelles, $10 \%$ SDS, sal K, and alb $\beta$ showed $\alpha$-helical structure, but in $2 \mathrm{mM}$ DPC or liposomes they presented $\beta$-sheet structure (Fig. 2). The percentage of the secondary structure of each peptide was calculated by SELCON3 (Table 2).

\section{Sequence alignment and structural prediction}

The amino acid sequences of sal $\mathrm{K}$ and alb $\beta$ are aligned in the antimicrobial peptide database. The highest similarity percentage between sal $\mathrm{K}$ and salivaricin $\mathrm{P}$ is $62 \%$. For alb $\beta$, the alignment result shows that sakacin $\mathrm{P}$ has the highest similarity percentage at $42 \%$ (Fig. 3). The amino acid sequences of sal K and alb $\beta$ were submitted to www.predictprotein.org to identify the predicted structure. The results show that sal $\mathrm{K}$ contains a mixed structure in different percentages of $\alpha$-helix, $\beta$-sheet, and random coil of $26 \%$, $19 \%$, and $55 \%$, respectively. One disulphide bond is predicted from Cys6 and Cys46. The transmembrane region at C-terminal was found from Ala18 to Leu47 (Fig. 4). For alb $\beta$, it contains mixed structure of $\alpha$ helix, $\beta$-sheet, and random coil of $17 \%, 34 \%, 49 \%$, respectively. One disulphide bond is detected between Cys 14 and Cys46. The transmembrane region is found from Gly 15 to Gly41.

\section{DISCUSSION}

Antimicrobial peptides show a wide range of activities, including antibiotic activity against gram-positive and gram-negative bacteria, antifungal activity, and antiviral activity. LAB are common bacteria that 

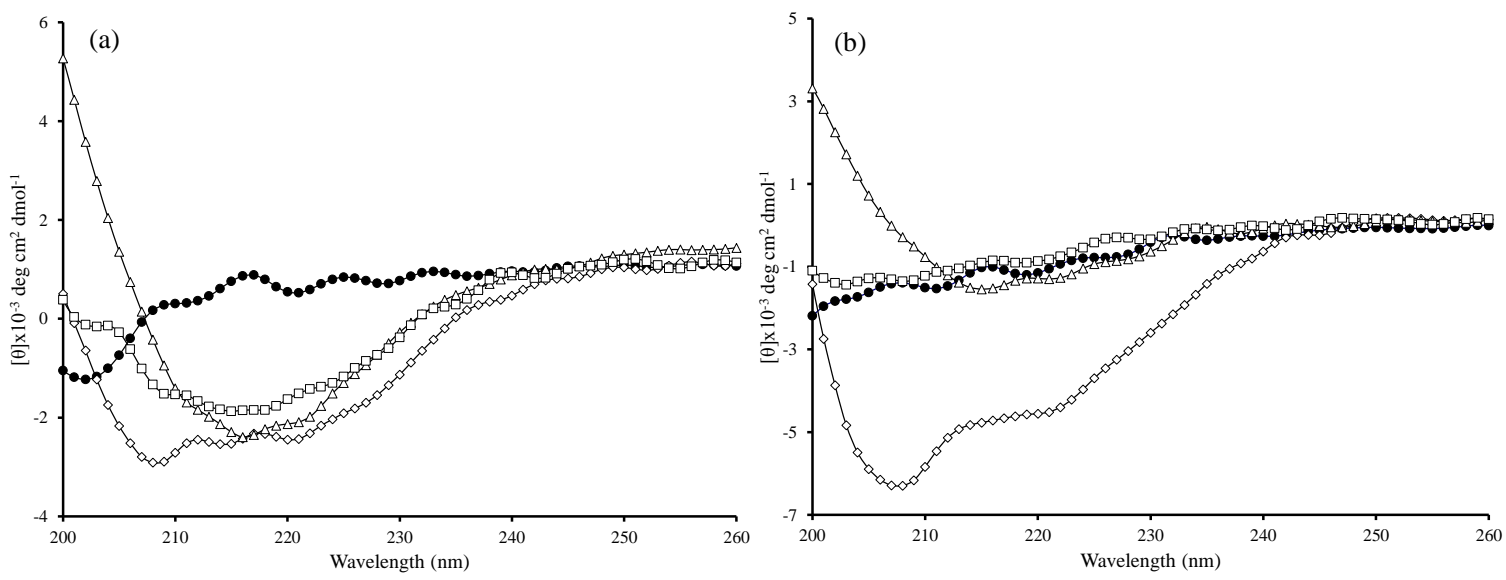

Fig. $2 \mathrm{CD}$ spectra of bacteriocins (a) sal $\mathrm{K}$ and (b) alb $\beta$. The peptide $(0.5 \mathrm{mg} / \mathrm{ml})$ was prepared in various buffers, Tris-Cl pH $9(\bullet), 10 \% \operatorname{SDS}(\diamond), 2 \mathrm{mM}$ DPC $(\triangle)$, and liposome $(\square)$.

Table 2 Percentage of secondary structure of sal K and alb $\beta$ calculated from SELCON3.

\begin{tabular}{llcccc}
\hline Peptide & Buffer & $\alpha$-helix & $\beta$-sheet & turn & unordered \\
\hline sal K & 10\% SDS & 35.6 & 16.4 & 25.3 & 23.3 \\
& 2 mM DPC & 17.6 & 46.9 & 2.4 & 31.1 \\
& Liposome & 44 & 24.7 & 18.3 & 13.5 \\
alb $\beta$ & $10 \%$ SDS & 44.6 & 15.1 & 15 & 26 \\
& 2 mM DPC & 0.08 & 34.7 & 24.8 & 32.2 \\
& Liposome & 3.7 & 47.1 & 16 & 21.5 \\
\hline
\end{tabular}

(a)

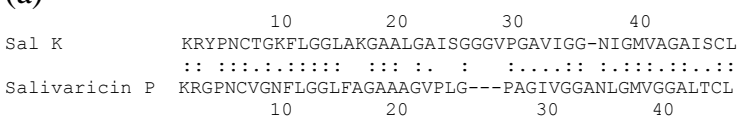

(b)

Alb $\beta$

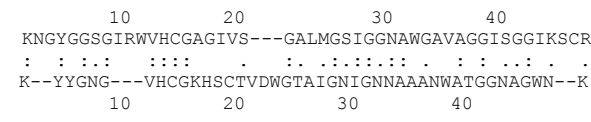

Fig. 3 Amino acid sequence alignment of (a) sal $\mathrm{K}$ and salivaricin $P$ and (b) alb $\beta$ and sakacin $P$.

can produce bacteriocins with the ability to kill other bacteria particularly food borne pathogen, E. faecalis, P. fluorescens and L. plantarum. In this study, sal K, bacteriocin from Lactobicillus salivarius K4, can inhibit food pathogens, E. faecalis JCM 5803, Lb. plantarum ATCC 14917, and Streptococcus sp. TISTR 1030. The alb $\beta$ shows activity against E. faecalis JCM 5803, Leuconostoc mesenteroides subsp. mesenteroides JCM 6124, Lb. sakei TISTR 890, Lb. plantarum ATCC 14917, and Streptococcus sp. TISTR 1030. These two peptides in moderate concentration display an activity against food borne (a)

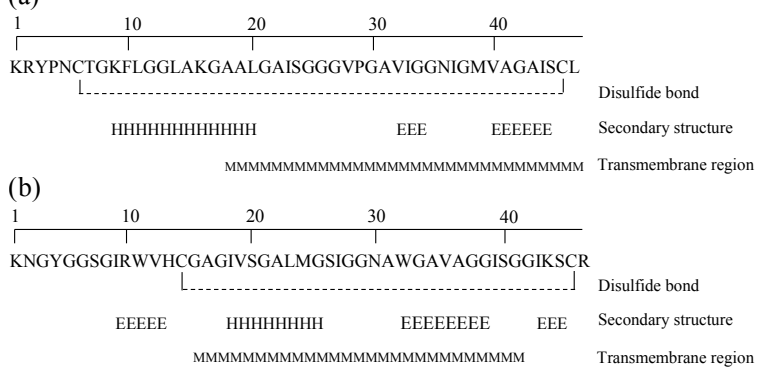

Fig. 4 Protein structure prediction of (a) sal K and (b) alb $\beta$ : broken lines indicate disulphide bond, $H=\alpha$-helix, $E=\beta$-sheet, blank $=$ random coil, $M=$ transmembrane region.

pathogens. Effective AMPs to be applied for human use should contain high antimicrobial activity but low cytotoxicity against eukaryotic cells ${ }^{4}$. These two peptides require high concentration to disrupt erythrocytes suggesting that they should not be harmful to eukaryotic cells. Sal K and alb $\beta$ are cationic peptides containing +4 charge of arginine and lysine. In a cationic antimicrobial peptide, the positively charged residues of $\mathrm{N}$-terminal interact with the negatively charged bacterial phospholipid-containing cell wall during initial binding ${ }^{3,6,11}$. After binding, the $\alpha$-helix in the middle part of peptide may penetrate the cell wall and permeabilize the membrane. Three models of pore-forming peptides have been proposed, barrelstave, carpet, and toroidal. In these three models, the peptide aligns and inserts into the membrane making it permeable to solutes. The composition of the cell membrane is a factor that determines the function of AMPs. Prokaryotic membranes have a 
high density of negative charge and are predominantly composed of phosphatidylgylcerol, cardiolipin, a phosphatidylserine. The mammalian membranes are composed of zwitterionic phospholipids, phosphotidylethanolamine, phosphatidylcholine and sphingomyelin ${ }^{4}$. In this study, the anionic micelles created by $10 \%$ SDS represent the prokaryotic cell membrane whereas DPC is the zwitterionic micelles representing an eukaryotic cell membrane ${ }^{24,25}$. The structure of these two peptides are found as helical structure in 10\% SDS micelles which corresponds to the protein prediction result with the residue 9-20 of sal $\mathrm{K}$ and the residue $18-25$ of alb $\beta$. The sequence similarity between sal $\mathrm{K}$ and salivaricin $\mathrm{P}$ was $62 \%$. Since the structure of salivaricin $\mathrm{P}$ has not yet been characterized, the 3D structure of either sal $\mathrm{K}$ or salivaricin $\mathrm{P}$ needs to be further investigated to explain the mechanism. The alignment result shows that alb $\beta$ and sakacin $P$ have a $42 \%$ sequence similarity. The sakacin $\mathrm{P}$ was produced in Lactobacillus sake Lb674. The residue $18-25$ of alb $\beta$ shows sequence similarity to the residue 18-33 of sakacin $\mathrm{P}$ (Fig. 3). This region of sakacin $\mathrm{P}$ was revealed as helical structure in a micellar environment by NMR technique ${ }^{26}$. This implied that at the residue $18-25$, alb $\beta$ can adopt a helix conformation similar to that of sakacin P. The tertiary structure of alb $\beta$ however needs to be examined to confirm the results of structural prediction. Other cationic peptides such as halocidin ${ }^{9}$ and indolicidin ${ }^{10}$ also show $\alpha$-helical structure in a micellar environment suggesting that this structure may be employed during pore formation. In halocidin, $\alpha$-helical structure was found when this peptide was in TFE and 10\% SDS. In DPC, zwitterionic micelle, sal $\mathrm{K}$ and alb $\beta$ performed structure majority in $\beta$-sheet. These results imply that the active conformation of sal $\mathrm{K}$ and alb $\beta$ is $\alpha$-helical structure. Since these two peptides can release the haemoglobin, they may be either $\alpha$-helix membrane pore formers or membrane disrupter as detergent-like model. The poreforming peptides or proteins such as, colicin ${ }^{27-30}$, Cry toxin $^{31-33}$, haemolysin $\mathrm{E}^{34}$ can disturb the transmembrane potential, $\mathrm{pH}$ gradient, and osmotic regulation of the cells which eventually leading to cell lysis. In the detergent-like model, protein will aggregate on the membrane until they could disrupt the structure of the lipid. Cyt1A is one of the proteins whose function has been hypothesized in detergent-like model ${ }^{35}$. The transmembrane region of these two peptides comprise hydrophobic residues as predicted from the results. Sal K amino sequence was similar to salivaricin $\mathrm{P}^{36}$. This peptide is also found in Lactobacillus salivarius DPC 6005 which is a different strain from this study.
The salivaricin $\mathrm{P}$ shows antimicrobial activity against E. faecalis similar to that of sal $\mathrm{K}$. The salivaricin $\mathrm{P}$ also exhibits activity against Staphylococcus aureus and Streptococcus thermophilus. The antimicrobial activity of sakacin $\mathrm{P}$ is found against $E$. faecalis, Leuconostoc mesenteroides, and $L b$. sakei ${ }^{37}$ similar to alb $\beta$. In contrast to alb $\beta$, sakacin $P$ shows no activity against $L b$. plantarum. No synergism of sal K and alb $\beta$ was observed in the antimicrobial activity or haemolysis assay. These results suggest that these two peptides may perform independent functions.

\section{CONCLUSIONS}

This study reveals the structure and function of sal $\mathrm{K}$ and alb $\beta$ from Lactobacillus salivarius $\mathrm{K} 4$ isolated from chicken intestine. The two antimicrobial peptides can adopt an unordered structure or $\alpha$-helix for antimicrobial activity. These bacteriocins may be applied to food to protect against food pathogen bacteria. The details of their structures are needed to be further investigated by NMR to better explain their mechanisms of action.

Acknowledgements: This work was supported by Kasetsart University Research and Development Institute.

\section{REFERENCES}

1. Hancock REW, Falla T, Brown M (1995) Cationic bactericidal peptides. Adv Microb Physiol 37, 135-75.

2. Devine DA, Hancock REW (2002) Cationic peptides: distribution and mechanisms of resistance. Curr Pharmaceut Des 8, 703-14.

3. Bulet P, Stöcklin R, Menin L (2004) Anti-microbial peptides: from invertebrates to vertebrates. Immunol Rev 198, 169-84.

4. Huang Y, Huang J, Chen Y (2010) Alpha-helical cationic antimicrobial peptides: relationships of structure and function. Protein Cell 1, 143-52.

5. Marshall SH, Arenas G (2003) Antimicrobial peptides: A natural alternative to chemical antibiotics and a potential for applied biotechnology. Electron J Biotechnol 6, 271-84.

6. Jenssen H, Hamill P, Hancock REW (2006) Peptide antimicrobial agents. Clin Microbiol Rev 19, 491-511.

7. Hancock REW, Chapple DS (1999) Peptide antibiotics. Antimicrob Agents Chemother 43, 1317-23.

8. Hwang PM, Vogel HJ (1998) Structure-function relationships of antimicrobial peptides. Biochem Cell Biol 76, 235-46.

9. Jang WS, Kim CH, Kim KN, Park SY, Lee JH, Son SM, Lee IH (2003) Biological activities of synthetic analogs of halocidin, an antimicrobial peptide from the tunicate Halocynthia aurantium. Antimicrob Agents Chemother 47, 2481-6. 
10. Falla TJ, Karunaratne DN, Hancock REW (1996) Mode of action of antimicrobial peptide indolicidin. J Biol Chem 271, 19298-303.

11. Powers JPS, Hancock REW (2003) The relationship between peptide structure and antibacterial activity. Peptides 24, 1681-91.

12. Brogden KA (2005) Antimicrobial peptides: pore formers or metabolic inhibitors in bacteria? Nat Rev Microbiol 3, 238-50.

13. Oren Z, Shai Y (1998) Mode of action of linear amphipathic $\alpha$-helical antimicrobial peptides. Biopolymers 47, 451-63.

14. Dean RE, O'Brien LM, Thwaite JE, Fox MA, Atkins H, Ulaeto DO (2010) A carpet-based mechanism for direct antimicrobial peptide activity against vaccinia virus membranes. Peptides 31, 1966-72.

15. Yang L, Harroun TA, Weiss TM, Ding L, Huang HW (2001) Barrel-stave model or toroidal model? A case study on melittin pores. Biophys $J$ 81, 1475-85.

16. Oscáriz JC, Pisabarro AG (2001) Classification and mode of action of membrane-active bacteriocins produced by gram-positive bacteria. Int Microbiol 4, 13-9.

17. Klaenhammer TR (1988) Bacteriocins of lactic acid bacteria. Biochimie 70, 337-49.

18. Jack RW, Tagg JR, Ray B (1995) Bacteriocins of grampositive bacteria. Microbiol Rev 59, 171-200.

19. O'Sullivan L, Ross RP, Hill C (2002) Potential of bacteriocin-producing lactic acid bacteria for improvements in food safety and quality. Biochimie 84, 593-604.

20. Pilasombut K, Sakpuaram T, Wajjwalku W, Nitisinprasert S, Swetwiwathana A, Zendo T, Fujita K, Nakayama J, et al (2006) Purification and amino acid sequence of a bacteriocins produced by Lactobacillus salivarius $\mathrm{K} 7$ isolated from chicken intestine. Songklanakarin J Sci Tech 28, 121-32.

21. Sreerama N, Venyaminov SYU, Woody RW (1999) Estimation of the number of $\alpha$-helical and $\beta$-strand segments in proteins using circular dichroism spectroscopy. Protein Sci 8, 370-80.

22. Wang G, Li X, Wang Z (2009) APD2: the updated antimicrobial peptide database and its application in peptide design. Nucleic Acids Res 37, D933-7.

23. Rost B, Yachdav G, Liu J (2004) The PredictProtein server. Nucleic Acids Res 32, suppl 2, W321-6.

24. Bourbigot S, Fardy L, Waring AJ, Yeaman MR, Booth V (2009) Structure of chemokine-derived antimicrobial peptide interleukin- $8 \alpha$ and interaction with detergent micelles and oriented lipid bilayers. Biochemistry 48, 10509-21.

25. Sayyed-Ahmad A, Khandelia H, Kaznessis YN (2009) Relative free energy of binding between antimicrobial peptides and SDS or DPC micelles. Mol Simul $\mathbf{3 5}$ 986-97.

26. Uteng M, Hauge HH, Markwick PRL, Fimland G, Mantzilas D, Nissen-Meyer J, Muhle-Goll C (2003) Three-dimensional structure in lipid micelles of the pediocin-like antimicrobial peptide sakacin $\mathrm{P}$ and a sakacin $\mathrm{P}$ variant that is structurally stabilized by an inserted C-terminal disulfide bridge. Biochemistry $\mathbf{4 2}$, 11417-26.

27. Parker MW, Pattus F, Tucker AD, Tsernoglou D (1989) Structure of the membrane-pore-forming fragment of colicin A. Nature 337, 93-6.

28. van der Goot FG, González-Mañas JM, Lakey JH, Pattus F (1991) A 'molten-globule' membrane-insertion intermediate of the pore-forming domain of colicin A. Nature 354, 408-10.

29. Parker MW, Postma JPM, Pattus F, Tucker AD, Tsernoglou D (1992) Refined structure of the poreforming domain of colicin A at $2.4 \AA$ resolution. $J \mathrm{Mol}$ Biol 224, 639-57.

30. Zakharov SD, Kotova EA, Antonenko YN, Cramer WA (2004) On the role of lipid in colicin pore formation. Biochim Biophys Acta 1666, 239-49.

31. Soberón M, Pardo L, Muñoz-Garay C, Sánchez J, Gómez I, Porta H, Bravo A (2010) Pore formation by Cry toxins. Adv Exp Med Biol 677, 127-42.

32. Jiménez-Juárez N, Muñoz-Garay C, Gómez I, SaabRincon G, Damian-Almazo JY, Gill SS, Soberón M, Bravo A (2007) Bacillus thuringiensis Cry1 Ab mutants affecting oligomer formation are non-toxic to Manduca sexta larvae. J Biol Chem 282, 21222-9.

33. Bravo A, Gill SS, Soberón M (2007) Mode of action of Bacillus thuringiensis Cry and Cyt toxins and their potential for insect control. Toxicon 49, 423-35.

34. Song L, Hobaugh MR, Shustak C, Cheley S, Bayley H, Gouaux JE (1996) Structure of staphylococcal $\alpha$ hemolysin, a heptameric transmembrane pore. Science 274, 1859-66.

35. Butko P (2003) Cytolytic toxin Cyt1A and its mechanism of membrane damage: data and hypotheses. Appl Environ Microbiol 69, 2415-22.

36. Barrett E, Hayes M, O'Connor P, Gardiner G, Fitzgerald GF, Stanton C, Ross RP, Hill C (2007) Salivaricin $\mathrm{P}$, one of a family of two-component antilisterial bacteriocins produced by intestinal isolates of Lactobacillus salivarius. Appl Environ Microbiol 73, 3719-23.

37. Mathiesen G, Huehne K, Kroeckel L, Axelsson L, Eijsink VGH (2005) Characterization of a new bacteriocin operon in sakacin P-producing Lactobacillus sakei, showing strong translational coupling between the bacteriocin and immunity genes. Appl Environ Microbiol 71, 3565-74. 